\title{
Control of the banana burrowing nematode using sisal extract
}

\author{
Fábio N. Jesus • Josilda C. A. Damasceno • \\ Dimmy H. S. G. Barbosa • Ricardo Malheiro • \\ José A. Pereira • Ana C. F. Soares
}

Accepted: 13 October 2014 / Published online: 31 December 2014

(C) INRA and Springer-Verlag France 2014

\begin{abstract}
The nematode Radopholus similis is a major pest in banana plantations worldwide. This nematode is actually controlled using synthetic, toxic nematicides. Alternative control methods are therefore needed. For instance the liquid byproduct of fiber extraction from sisal (Agave sisalana) may be used as a nematicide. Here we tested the nematicidal activity of the sisal residue, fresh or fermented, on $R$. similis in banana plants. We measured immobility and mortality effects by nematode immersion in an aqueous solution of sisal residue for 24 and $48 \mathrm{~h}$. Nematode control was also evaluated in the Grand Naine banana plants under greenhouse conditions using soil amendments of residues. We measured plant growth, pseudostem diameter, the number of leaves, and the dry weight of the aerial parts, corm and roots, as well as factors related to nematode control such as the level of damage, the population of $R$. similis in roots and soil, and nematode reproduction factors. Our results show that the sisal residue efficiently controlled $R$. similis in vitro, displaying mortality rates of $99.2 \%$ for the fresh residue. The damage caused by $R$. similis on plants was similar for the treatment with the sisal residue at a concentration of $25 \%$ and with the nematicide. This is the first report on the nematicidal effect of the sisal liquid residue on the banana burrowing nematode. This by-
\end{abstract}

F. N. Jesus · J. C. A. Damasceno · A. C. F. Soares $(\bowtie)$

Center for Agricultural, Environmental and Biological Sciences,

Federal University of Recôncavo da Bahia (UFRB), University

Campus, Cruz das Almas 44380-000, Bahia, Brazil

e-mail: acsoares@ufrb.edu.br

D. H. S. G. Barbosa

Embrapa Cassava and Fruits, Brazilian Agricultural Research

Corporation, Cruz das Almas 44380-000, Bahia, Brazil

R. Malheiro $\cdot$ J. A. Pereira

Mountain Research Centre (CIMO), School of Agriculture, Polytechnic Institute of Bragança, Campus de Santa Apolónia, Apt. 1172, 5301-854 Bragança, Portugal product presents the potential for the development of new alternatives for nematode control, with a low-cost and lowenvironmental risk plant nematicide.

Keywords Musa spp. · Agricultural wastes $\cdot$ Nematicidal activity $\cdot$ Agave sisalana $\cdot$ Radopholus similis

\section{Introduction}

Several nematode species attack banana plantations; Radopholus similis (Cobb, 1893) Thorne, 1949, is known as the burrowing nematode and is the main banana pest species worldwide, causing severe damage and economic loss (Quénéhervé 2009). This migratory endoparasitic nematode causes root and corm tissue cavities that evolve to form necrotic lesions (Fig. 1a) that affect the ability of the plant to uptake water and nutrients, resulting in the reduced development of banana bunches and reduced fruit yield (Aravind et al. 2010).

Plant-parasitic nematode control has been based on chemical soil fumigants and nematicides (Candido et al. 2008). However, several problems have been associated with the use of these pesticides, including the contamination of soil, plants, and groundwater and health risks to animals, farmers, and consumers (López-Lima et al. 2013).

As a result, the demand for organic residues or agricultural by-products that provide nematode control in agricultural systems as an alternative to synthetic nematicides has increased worldwide (Wezel et al. 2014). Several compounds of plant origin exhibit nematicidal activity, are cost effective and environmentally safe (Aoudia et al. 2012), and can be used in organic farming systems (Oka et al. 2000). The development of agricultural practices that integrate biofertilizers and natural products has been reported to be a method of increasing sustainable food production (Wezel et al. 2014). 


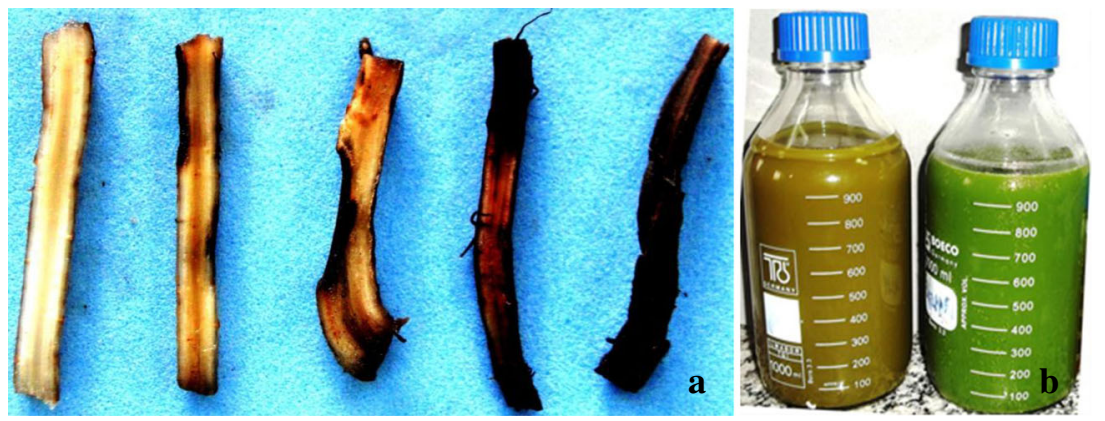

Fig. 1 Roots of banana plants with different levels of damage caused by Radopholus similis (a). Fermented (b, left side) and fresh (b, right side) sisal (Agave sisalana) liquid residues (b). The liquid residue is obtained after squeezing and filtering the sisal solid residue, a by-product obtained from the decortication process for fiber extraction, in which leaves are crushed and beaten by a rotating wheel equipped with blunt knives until only fibers remained
Long-term soil amendment of effective microorganism compost as an alternative to mineral fertilizers benefits free-living nematode community structure in soil as well as wheat biomass and grain yield (Hu and Qi 2013). Other strategies, such as biocontrol with Paecilomyces sp., leguminous crop rotation, and a combination of both, have been reported as efficient in controlling populations of the potato cyst nematode Globodera rostochiensis (López-Lima et al. 2013).

Brazil is the main sisal fiber producer in the world, and the state of Bahia is responsible for $95.5 \%$ of sisal production in this country. Sisal (Agave sisalana Perrine ex Engelm) originated from Mexico and is well adapted to the semiarid areas of northeastern Brazil. Sisal has become one of the most important crops for the economy of the semiarid region of Bahia State and the main source of income for several hundred rural families in this region. Sisal fiber is the main product from this crop, but it only represents approximately $4 \%$ of the leaf fresh weight; the solid and liquid residues constitute the other $96 \%$ of the plant, including $81 \%$ liquid residue (Suinaga et al. 2006). This agricultural by-product has been used by farmers for goat and cattle feeding in small quantities, but the majority of the residue is left abandoned in rural properties without any treatment.

Plants belonging to the genera Agave have reportedly shown biocidal activity against nematodes from goats and lambs (Botura et al. 2011; Domingues et al. 2010; Silveira et al. 2012). Sisal liquid residue is composed of secondary metabolites such as alkaloids, phenolic compounds, glycosidic saponins, flavonoids, and tannins (Chen et al. 2011). These substances are related to plant defense mechanisms and have also been associated with biocidal activities, including nematicidal activity. Therefore, in the present work, we aimed to study the sisal liquid residue for controlling $R$. similis under in vitro conditions and in the banana plant cv. 'Grand Naine.' The present work also explored a new research line that may add value to sisal by-products and develop bioactive products for agricultural use.

\section{Materials and methods}

\subsection{R. similis inoculum preparation}

The $R$. similis population was obtained from soil and root samples of infected banana plants from a commercial plantation in the municipality of Bom Jesus da Lapa, Bahia State, Brazil. Nematode extraction was performed according to the methods described by Jenkins (1964) for soil samples and by Hussey and Barker (1973) for root samples. The identification of $R$. similis was based on its morphological characteristics (Mai and Mullin 1996).

The inoculum multiplication was performed in 'Prata Anã' banana plants obtained from in vitro micropropagation and acclimatization at the Campo Plant Biotechnology Company, Cruz das Almas, Bahia. The plants were transplanted to pots containing $3 \mathrm{~kg}$ of a sterile mixture of soil and sand (proportion $2: 1 v / v$ ). For inoculation, three 2-cm-depth holes were perforated into the soil close to the plant roots, and 800 juveniles of $R$. similis were inoculated per plant. The inoculated plants were grown for 4 months with daily irrigation in a greenhouse located at the Federal University of Recôncavo da Bahia (UFRB), Cruz das Almas campus. After this period, the $R$. similis juveniles were extracted from the banana roots according to the method described by Coolen and D'Herde (1972) and Jenkins (1964). The aqueous suspension of $R$. similis juveniles was counted in a Peters chamber under a microscope, and the suspension was adjusted to 150 juveniles per $\mathrm{mL}$ by dilution with sterile distilled water.

\subsection{Liquid fresh and fermented residues of sisal}

Sisal liquid residue was obtained from a sisal production area in the city of Valente, Bahia State. The leaves were subjected to a decortication process in which they were crushed and beaten by a rotating wheel equipped with blunt knives until only fibers remained. From this process, the leaf decortication 
residue (mixed solid and liquid material) was obtained. This mixture was squeezed and filtered with cheesecloth, and the liquid portion was transferred to plastic bags and kept on ice in Styrofoam boxes for transportation to the laboratory at UFRB. In the laboratory, a portion of this residue was kept in a freezer at $4{ }^{\circ} \mathrm{C}$, and another portion was maintained in plastic bottles for 4 days at room temperature $\left(28 \pm 2{ }^{\circ} \mathrm{C}\right)$ until fermentation and was then placed in a freezer.

\subsection{In vitro tests with liquid fresh and fermented residues} of sisal

The in vitro tests were conducted in a completely randomized experimental design using a $5 \times 2+2$ factorial scheme that included the residue diluted to five concentrations $(5,10,15$, 20 , and $25 \%$ ), two residues (fresh and fermented), and two control treatments with five replications. The negative control was water, and the positive control was a synthetic nematicide (Carbofuran-Furadan 350 SC, FMC Corporation, NY, USA; $350 \mathrm{~g}$ active ingredient per $\mathrm{L}$ ). The bioassays were conducted in microcentrifuge tubes with $100 \mu \mathrm{L}$ of an aqueous suspension containing 150 juveniles of $R$. similis and $1000 \mu \mathrm{L}$ of residue. This residue (fresh or fermented) was diluted in sterile distilled water for the concentrations described above. The bioassays were incubated at $28{ }^{\circ} \mathrm{C}$ in a growth chamber. After $24 \mathrm{~h}$ of nematode exposure, the residue was removed with the use of a sieve, and the nematodes were washed with sterile distilled water and transferred to a Peters chamber. The immobile individuals were immediately counted under a microscope. These nematodes were again incubated in water for $24 \mathrm{~h}$ at $28{ }^{\circ} \mathrm{C}$ and then counted. The individuals who were immobile after $24 \mathrm{~h}$ of exposure to water were considered dead.

\subsection{In vivo control of $R$. similis in banana plants}

This experiment was conducted in a greenhouse from 15 December 2013 to 22 February 2014, in the city of Cruz das Almas, UFRB campus. An experiment was conducted with the fresh and fermented sisal liquid residue and the banana plant cv. 'Grand Naine.' Micropropagated banana plants were obtained from the Campo Plant Biotechnology Company after they had been acclimatized in a greenhouse for 30 days. The plants were transplanted to plastic pots with a mixture of soil and sand (proportion 2:1 v/v) that had been sterilized in an autoclave at $120{ }^{\circ} \mathrm{C}$ for $1.5 \mathrm{~h}$ twice on separate days. Twenty days after transplantation, the plants were inoculated with 800 juveniles of $R$. similis per plant. The experimental design was entirely randomized in a $5 \times 2+2$ factorial scheme that included five concentrations of the residue $(5,10,15,20$, and $25 \%$ ), two residues (fresh and fermented), two control treatments, ten replications, and one plant per pot as the experimental unit. The negative control consisted of soil with water, and the positive control consisted of soil with a synthetic nematicide (Carbofuran-Furadan $350 \mathrm{SC} ; 350 \mathrm{~g}$ active ingredient per L). Each pot with the mixture of soil and sand was amended with $100 \mathrm{~mL}$ of liquid residue and diluted in water to the experimental concentrations as described above. The plants were grown in the greenhouse with daily irrigation and harvested 45 days after inoculation. The plant height, stem diameter, number of leaves, and dry weight of leaves, corm, and roots were recorded. The percentage of root necrosis was evaluated using the scale of Bridge and Gowen (1993). The nematodes were extracted from the roots according to the method of Hussey and Barker (1973) and from the soil according to the method of Jenkins (1964) and were then counted. The nematode population was estimated for the total amount of soil and roots per pot, which represented an experimental unit. The reproduction factor (RF) (Seinhorst 1967) was estimated for each replication $(\mathrm{RF}=$ Final population/Initial population), with the final population corresponding to the total number of nematodes found in the soil and roots.

\subsection{Statistical analysis}

An analysis of variance and linear regression were used for the data analysis to evaluate the effect of different concentrations of sisal residue on nematode control. A comparison between the residues and control treatment was performed through orthogonal contrast. The statistical software Statistical Analysis System (SAS) version 9.2 was used.

\section{Results and discussion}

3.1 In vitro tests with fresh and fermented sisal liquid residue

Both fresh and fermented residues caused significant $(P \leq$ 0.01 ) mortality among the juveniles of $R$. similis under in vitro conditions. The application of the residue, both fresh and fermented, caused a linear increase in the immobility and mortality of $R$. similis with increasing concentrations of the residues up to the maximum tested concentration of $25 \%$ (Table 1). Higher concentrations were not evaluated because preliminary studies showed that the banana plant $\mathrm{cv}$. 'Grand Naine' grown in soil amended with the sisal residue at concentrations above $25 \%$ developed symptoms of toxicity.

The minimum concentration (5\%) of the fresh residue caused the immobility of $84.9 \%$ and mortality of $90.1 \%$ of the juveniles, and an increase of approximately $0.7 \%$ immobility and $0.5 \%$ mortality was observed for each $1 \%$ increase in residue concentration. A $5 \%$ concentration of the fermented residue caused the immobility of $70.6 \%$ and the mortality of $87.6 \%$ of the juveniles, and an increase of $0.11 \%$ of immobility and $0.5 \%$ mortality was observed for each $1 \%$ 
Table 1 Equations with respective coefficients of determination and significance for all of the evaluated factors in the assays with fresh and fermented sisal liquid residue for the control of Radopholus similis in the banana plant cv. 'Grand Naine'

\begin{tabular}{|c|c|c|c|c|c|c|}
\hline \multirow[t]{2}{*}{ Mortality (h) } & \multicolumn{3}{|l|}{ Fresh residue } & \multicolumn{3}{|l|}{ Fermented residue } \\
\hline & Equation & $R^{2}$ & $P$ & Equation & $R^{2}$ & $P$ \\
\hline 24 & $\hat{y}=81.302+0.715 x$ & 0.936 & $\leq 0.01^{\mathrm{a}}$ & $\hat{y}=70.013+0.110 x$ & 0.855 & $\leq 0.01^{\mathrm{a}}$ \\
\hline 48 & $\hat{y}=87.570+0.502 x$ & 0.859 & $\leq 0.01^{\mathrm{a}}$ & $\hat{y}=85.285+0.468 x$ & 0.933 & $\leq 0.01^{\mathrm{a}}$ \\
\hline
\end{tabular}

${ }^{\text {a }}$ Significant at $1 \%$

increase in residue concentration. For the highest concentration $(25 \%)$, the $R$. similis immobility rates were $99.2 \%$ (fresh residue) and $72.8 \%$ (fermented residue) and the mortality rates were $97 \%$ (fresh residue) and $100 \%$ (fermented residues). These results are clearly higher than those observed in the negative control (water). After 24 and $48 \mathrm{~h}$ in water, the immobility rates for nematodes were 3.9 and $3.6 \%$, respectively. From these results, it is clear that both of the sisal residues exerted a toxic effect on $R$. similis juveniles.

Significant differences were found for the concentrations of each residue tested at $48 \mathrm{~h}(P=0.001$ for fresh residue; $P<0.001$ for fermented residue). In both residues, concentrations of 20 and $25 \%$ caused significantly higher mortality compared with concentrations of $5 \%$ for each residue and $10 \%$ for the fermented residue. In the fresh residue, the effect of the $20 \%$ concentration was not significantly different from that of the $10 \%$ concentration $(P>0.05)$.

The nematicidal effect of sisal residue was observed for all of the tested concentrations, and nematodes that were transferred to water after exposure to this residue (fresh and fermented) did not recover and ultimately died.

A comparison of both residues in vitro showed that the fresh residue was more efficient in causing nematode immobility and mortality; however, both residues can be considered effective in causing the mortality of $R$. similis juveniles. Significantly higher mortality was observed with the application of the fresh residue compared with the fermented residue at $20 \%(P=0.001)$ and $25 \%(P=0.002)$. A comparison of both residues at concentrations lower than $20 \%$ did not show significant differences: $P=0.194$ for $5 \%, P=0.379$ for $10 \%$, and $P=0.002$ for $15 \%$.

These results demonstrate the potential of the sisal liquid residue in the control of $R$. similis and indicate that the fermentation process does not inactivate this residue or the components responsible for the nematicidal effect. Nevertheless, the fresh residue is a better option for the control of $R$. similis in vitro because significantly higher mortality rates were observed with concentrations of 20 and $25 \%$.

A comparison of the effect of a sisal residue and a commercial nematicide for controlling $R$. similis showed no significant differences $(P>0.05)$ in nematode immobility and mortality when the sisal residue was used at the highest concentrations (25\%), which indicates the nematicidal effect of the sisal liquid residue (Table 2). Therefore, the toxic effects of synthetic nematicide and sisal residues on $R$. similis juveniles are similar.

Several studies on ruminants have demonstrated the effect of plant extracts on the development and mortality of nematode juveniles (Alonso-Diaz et al. 2008) and adults (Hounzangbe-Adote et al. 2005). Silveira et al. (2012) tested a sisal liquid residue for in vitro egg hatching and juvenile development of goat gastrointestinal nematodes and demonstrated the antiparasitic effect of this residue. Domingues et al. (2010) conducted in vitro tests and observed a reduction of greater than $95 \%$ in the number of juveniles of the gastrointestinal nematode Haemonchus spp. treated with sisal extracts.

3.2 In vivo control of $R$. similis with fresh and fermented sisal residue in banana plants

Fresh and fermented sisal liquid residue produced significant $(P \leq 0.01)$ effects on plant growth (plant height, pseudostem diameter, number of leaves, and dry weight of aerial parts, corms, and roots) (Fig. 2). The application of the fresh and fermented sisal residue at the estimated concentrations of 8.3 and $14.8 \%$, respectively, promoted increases of 6 and $17 \%$ in the plant height for plants inoculated with $R$. similis compared with the treatment without residue. The pseudostem diameter also increased with residue concentrations of up to $6 \%$ (fermented residue) and $20.5 \%$ (fresh residue) (Fig. 2b).

There was a reduction in the number of banana leaves with the application of both residues $(P \leq 0.01)$. For the dry weight of the roots, corms, and aerial parts, a quadratic response was observed. Residue at low concentrations promoted an increase in the dry weight of the roots (Fig. 2e), corms, and aerial parts compared with the control treatment without the residue. Nasu et al. (2010) observed an increase in plant dry weight in tomato plants infected with Meloidogyne incognita when the by-product of Manihot esculenta Crantz was used in concentrations of 25 and $50 \%$. 
Table 2 Estimates of contrasts vs. nematicide doses of the sisal residues and significance for all of the evaluated factors in the control of Radopholus similis in vitro (mortality at 24 and $48 \mathrm{~h}$ ) and in vivo in the banana plant cv. 'Grand Naine'

\begin{tabular}{|c|c|c|c|c|c|c|c|c|c|c|c|c|c|}
\hline \multirow[t]{2}{*}{ Contrasts } & \multicolumn{2}{|l|}{ Mortality } & \multirow[t]{2}{*}{$\mathrm{HE}$} & \multirow[t]{2}{*}{ PMD } & \multirow[t]{2}{*}{$\mathrm{NF}$} & \multirow[t]{2}{*}{ RW } & \multirow[t]{2}{*}{ RMW } & \multirow[t]{2}{*}{ SW } & \multirow[t]{2}{*}{ LD } & \multirow[t]{2}{*}{ PNR } & \multirow[t]{2}{*}{ PNS } & \multirow[t]{2}{*}{ TPN } & \multirow[t]{2}{*}{ FR } \\
\hline & $24 \mathrm{~h}$ & $48 \mathrm{~h}$ & & & & & & & & & & & \\
\hline $5 \%$ vs. nematicide & $-20.934^{\mathrm{a}}$ & $-11.730^{\mathrm{a}}$ & $0.125^{\mathrm{b}}$ & $-0.395^{\mathrm{a}}$ & $-0.900^{\mathrm{b}}$ & $-15.155^{\mathrm{a}}$ & $-1.625^{\mathrm{a}}$ & $-1.046^{\mathrm{b}}$ & $0.760^{\mathrm{a}}$ & $1120.25^{\mathrm{a}}$ & $204^{\mathrm{a}}$ & $1274.25^{\mathrm{a}}$ & $1.593^{\mathrm{a}}$ \\
\hline $10 \%$ vs. nematicide & $-14.206^{\mathrm{a}}$ & $-7.637^{\mathrm{a}}$ & $0.175^{\mathrm{b}}$ & $-0.365^{\mathrm{a}}$ & $-1.000^{\mathrm{b}}$ & $-16.328^{\mathrm{a}}$ & $-1.006^{\mathrm{a}}$ & $-2.061^{\mathrm{a}}$ & $0.295^{\mathrm{a}}$ & $743.75^{\mathrm{a}}$ & $148^{\mathrm{a}}$ & $841.75^{\mathrm{a}}$ & $1.052^{\mathrm{a}}$ \\
\hline $15 \%$ vs. nematicide & $-13.186^{\mathrm{a}}$ & $-4.914^{\mathrm{a}}$ & $0.225^{\mathrm{b}}$ & $-0.465^{\mathrm{a}}$ & $-1.200^{\mathrm{c}}$ & $-16.011^{\mathrm{a}}$ & $-1.702^{\mathrm{a}}$ & $-2.147^{\mathrm{a}}$ & $0.225^{\mathrm{a}}$ & $529.50^{\mathrm{a}}$ & $80^{\mathrm{a}}$ & $559.5^{\mathrm{a}}$ & $0.699^{\mathrm{a}}$ \\
\hline $20 \%$ vs. nematicide & $-9.632^{\mathrm{a}}$ & $-3.243^{\mathrm{a}}$ & $-1.400^{\mathrm{b}}$ & $-0.595^{\mathrm{a}}$ & $-2.400^{\mathrm{a}}$ & $-19.245^{\mathrm{a}}$ & $-1.917^{\mathrm{a}}$ & $-2.956^{\mathrm{a}}$ & $0.205^{\mathrm{a}}$ & $347.5^{\mathrm{a}}$ & $58^{\mathrm{a}}$ & $355.5^{\mathrm{a}}$ & $0.443^{\mathrm{a}}$ \\
\hline $25 \%$ vs. nematicide & $-7.079^{\mathrm{b}}$ & $-1.795^{\mathrm{b}}$ & $-3.275^{\mathrm{a}}$ & $-0.650^{\mathrm{a}}$ & $-2.700^{\mathrm{a}}$ & $-21.726^{\mathrm{a}}$ & $-2.101^{\mathrm{a}}$ & $-2.956^{\mathrm{a}}$ & $0.111^{\mathrm{b}}$ & $92.25^{\mathrm{b}}$ & $20^{\mathrm{b}}$ & $62.25^{\mathrm{b}}$ & $0.077^{\mathrm{b}}$ \\
\hline
\end{tabular}

$H E$ height, $P M D$ pseudostem diameter, $N F$ number of leaves, $R W$ root weight, $R M W$ rhizome weight, $S W$ shoot weight, $L D$ level of damage, $P N R$ population of nematodes in roots, $P N S$ population of nematodes in soil, TPN total population of nematodes, $F R$ factor of reproduction

${ }^{\text {a }}$ Significant at $1 \%(P \leq 0.01)$

${ }^{\mathrm{b}}$ Not significant at $5 \%(P>0.05)$

${ }^{\mathrm{c}}$ Significant at $5 \%(P \leq 0.05)$

For plants treated with the fermented residue, there was a linear decrease in the plant growth parameters with increased residue concentrations. The fermented residue presented toxic effects to the banana plants (Fig. 2) in concentrations above $25 \%$, which were not observed in the fresh residue, suggesting the development of toxic components during the fermentation process. A phytochemical screening of sisal residue may detect the fractions that cause phytotoxic effects and those that are the most effective for nematode control.

With regard to plant growth, no significant difference was observed between the effect of the sisal residue and nematicide on the plant height, number of leaves, and dry weight of the aerial parts for residue concentrations of up to 20,15 , and $5 \%$, respectively. However, the treatment with the nematicide was superior to all of the treatments with the residue for pseudostem diameter and dry weight of the roots and rhizome (Table 2).

Populations of $R$. similis in the soil and in roots were reduced with the use of both the fresh and fermented sisal residues $(P \leq 0.01)$. The application of fresh and fermented residues at a concentration of $25 \%$ was more efficient and caused a reduction in the number of juvenile individuals of 66 and $80 \%$ in the soil and 84 and $77 \%$ in the roots, respectively, compared with plants treated with water (Fig. 3c, d).

Fresh and fermented sisal residue at an estimated concentration of approximately $17 \%$ promoted a reduction in root damage caused by $R$. similis of 80 and $90 \%$, respectively, compared with the treatment with water $(0 \%)$ (Fig. 3a). The level of damage represents the severity of necrosis caused by $R$. similis on the banana root cortex. These results demonstrate the efficient inhibition of nematode parasitic action on banana roots. These root lesions are formed as a result of cavities and tunnels created by the nematode feeding habits in the root cytoplasm and cortical cells, causing cell wall collapse and affecting the plant's water and nutrient uptake and possibly leading to the toppling of flowering plants (Kosma et al. 2011).

The final population of $R$. similis and reproduction factor showed a linear decline with increases in the concentrations of fresh and fermented sisal residue. The $25 \%$ concentration was the most efficient and showed a reduction of $78 \%$ in the total population and reproduction factor of $R$. similis in plants treated with a sisal residue compared with plants that did not receive the residue $(0 \%)$. A comparison of the highest $(25 \%)$ and lowest (5\%) applied concentrations demonstrates that the highest concentration promoted a mortality rate of $74 \%$ for both the fresh and fermented residues (Fig. 3b, e).

A comparison of plants treated with the residue and nematicide showed no significant difference when the residue was applied at the highest concentration (25\%) for all of the evaluated parameters (level of damage, nematode population in the soil and roots, total population, and reproduction factor). However, the nematicide was superior to the residue at concentrations of $20 \%$ or lower (Table 2 ).

Nasu et al. (2010) demonstrated that the nematicide carbofuran was efficient in controlling $M$. incognita under greenhouse conditions, and its effects were not significantly different from those of the sub-product of cassava processing in concentrations of 10 and $25 \%$.

The nematicidal effect of the sisal liquid residue may be associated with secondary metabolites present in this residue, such as alkaloids, saponins, terpenes, flavonoids, and glycosides, which have shown antiparasitic activity against gastrointestinal nematodes (Botura et al. 2013) as well as other biological activities (Francis et al. 2002). Among the bioactive substances present in sisal residue, saponins have been associated with the nematicidal effect of sisal residue against nematode juveniles (Francis et al. 2002). The presence of 
Height (cm)

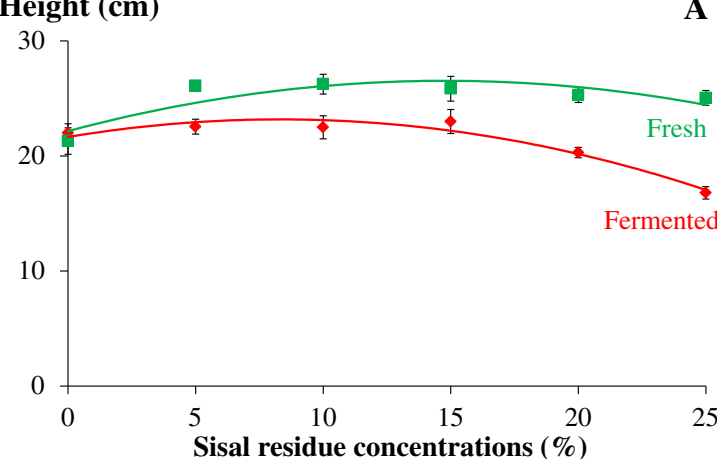

A

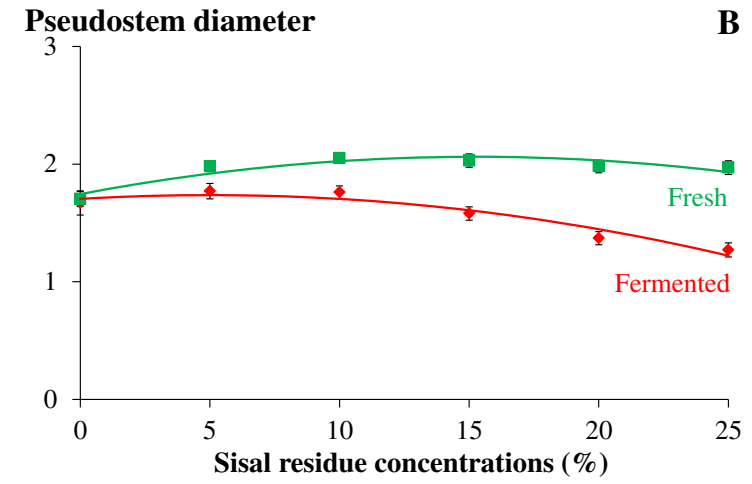

C Rhizome weight (g)

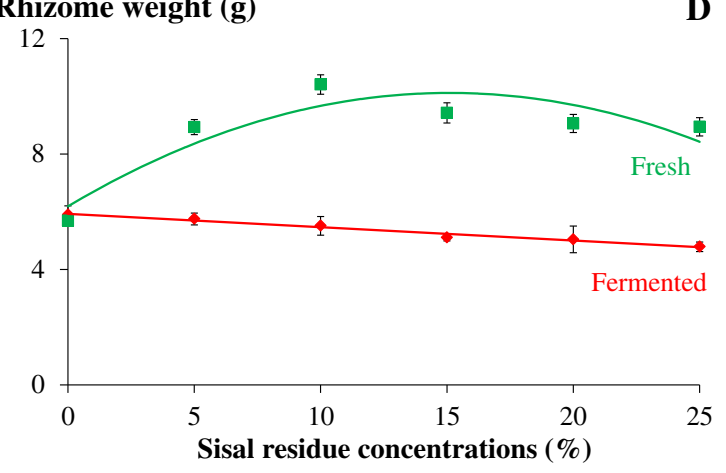

E Shoots weight (g)

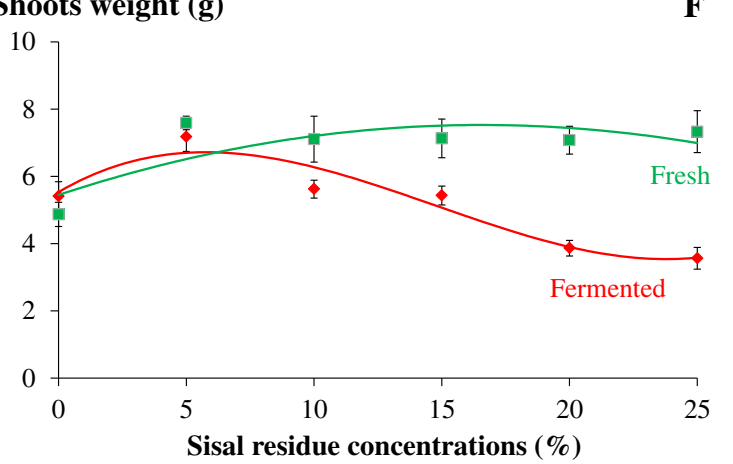

weight (f). The application of the sisal fresh residue proved to have a lower impact on the banana plants than the fermented residue. Fermented residue application in banana plants caused a considerable reduction in the number of leaves and weight of the roots and shoots

in the roots of Hyptis suaveolens and Ocimum gratissimum and in the leaves of Tagetes erecta have saponins and flavonoids that reduce $M$. incognita populations in tomato plants. Kosma et al. (2011) also showed that neem (Azadirachta indica) seed extracts have nematicidal effects against $R$. similis and reported the presence of saponins.

These results indicate the efficient control of $R$. similis with either fresh or fermented sisal residue, which can be used as an alternative for nematode control in sustainable agricultural production systems that require natural products that are less detrimental to the environment. Fresh sisal residue revealed a higher potential in the control of $R$. similis in planta compared with the fermented residue, which was consistent with the results obtained in vitro. In addition, the use of fresh residue 


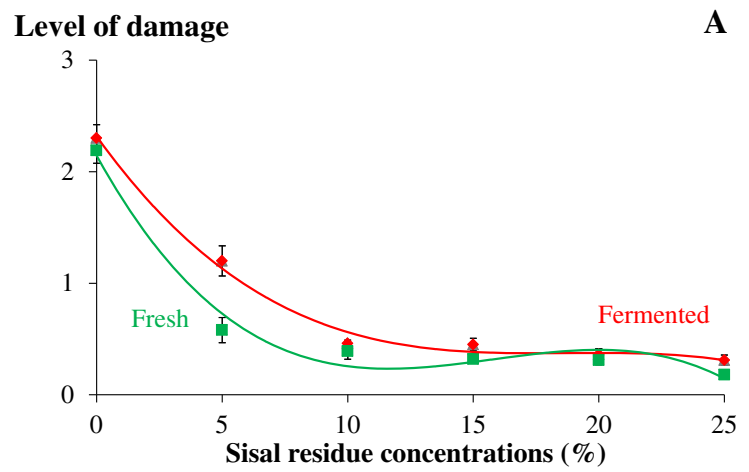

A Factor of reproduction

B

Soil population

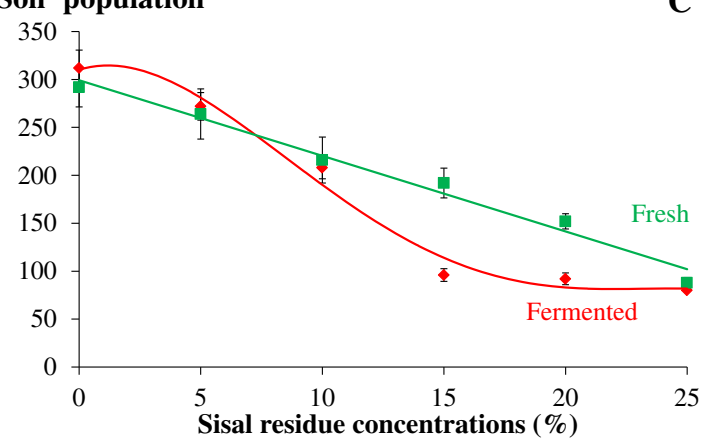

Total population

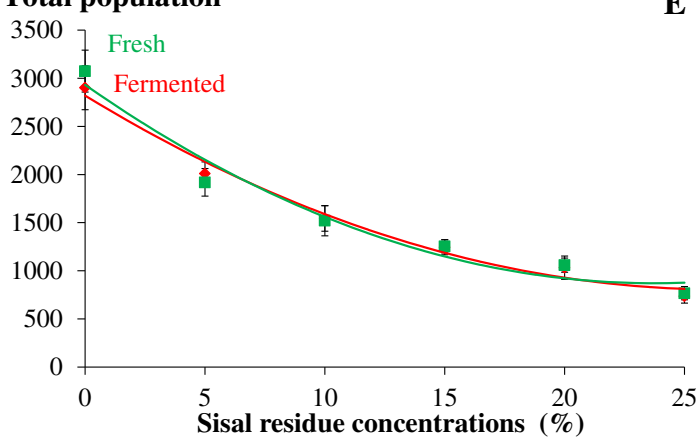

Fig. 3 Level of damage (root lesions quantified with the scale of Bridge and Gowen 1993) (a), factor of reproduction (FR=Final population/ Initial population) (b), soil population (c), root population (d), and total population (e) of Radopholus similis juveniles, per pot or experimental unit, in the banana plant cv. 'Grand Naine' and soil, with the application

is advantageous because farmers can apply sisal by-product immediately without the need for additional fermentation processes. However, we have also shown that the fermented sisal residue can be used as a nematicide. We believe that this agricultural residue may be an effective natural alternative to synthetic nematicides for controlling $R$. similis in banana plantations. In addition to providing excellent levels of nematode mortality, the influence of sisal residue on the plant growth parameters was reduced. From an economic perspective, synthetic nematicides are high-cost agricultural inputs, whereas a sisal residue is a highly abundant raw material that is cheap, easily obtained, available all year, and derived from natural sources. In addition, new alternatives for using this

E

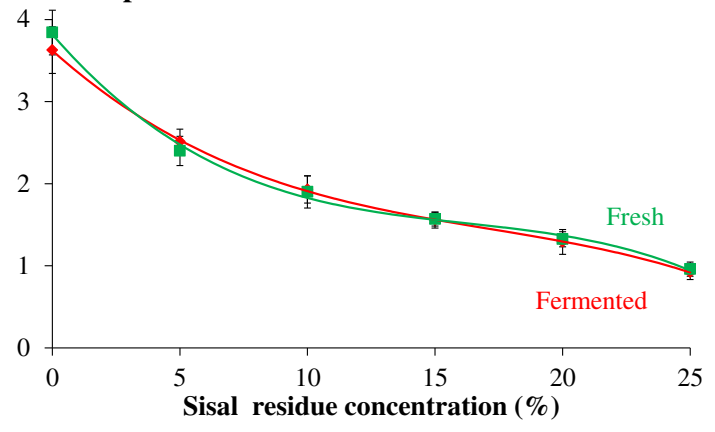

Root population

D

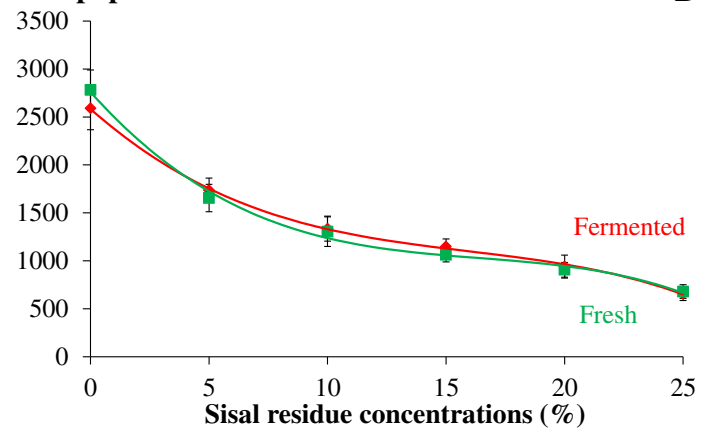

of the fresh and fermented sisal residues at different concentrations (mean of ten replications \pm standard error). Root damage, nematode reproduction factor, $R$. similis in the soil and root, and $R$. similis total population were reduced considerably in response to the applied concentration of fresh and fermented residue

residue have been reported in this work, and they can greatly benefit small family-based sisal farmers. Many sisal farmers plant sisal as a subsistence crop with fiber extraction as the only source of income; however, they retain huge amounts of this residue in the field without any treatment or proper use or disposal. Adding value to this residue can represent a new source of income for sisal farmers. There is an increasing worldwide demand for the development of agricultural practices that can increase food production in an environmentally friendly, socially responsible, and economically beneficial manner (Wezel et al. 2014). Our work presents the development of one such practice. From the consumer's perspective, a reduction in the application of synthetic nematicides will 
reduce the probability of incorporating residues in fruits and vegetables (Tixier et al. 2007), eliminate the risk of possible long-term health problems because of prolonged exposure to these pesticides, and foster trust and confidence. The replacement of nematicides with natural sources, such as sisal residue, will also reduce pollution and improve ecological infrastructures (Castillo et al. 2000). Sisal liquid residue is a leaf decortication by-product with the potential to generate income for sisal farmers in the semiarid regions of Brazil; thus, its use as an agricultural input should be further investigated for the development of nematicides.

\section{Conclusions}

Sisal liquid residue, either fresh or fermented, was efficient in the control of $R$. similis both in vitro and in banana plants. However, the fermented residue presented phytotoxicity toward banana plants when used in concentrations above $25 \%$. Therefore, this phytotoxic effect should be further investigated for the utilization of fermented sisal residue in crop production and protection. The fresh residue appeared to be more efficient for nematode control and presented lower toxicity to the banana plants. This residue is a by-product from sisal leaf decortication that is left in the environment without any further treatment or used in limited amounts for animal feeding and crop fertilization. The effective nematicidal activity of this agricultural residue has been demonstrated in the present work. Its potential for the development of bioactive products represents potential to generate income for the poor rural family farmers in the semiarid regions of Bahia State, Brazil, through the production of sisal for fiber extraction. Furthermore, the development of low-cost plant nematicides with a reduced environmental impact provides the opportunity to add value to sisal residues for use in sustainable agricultural systems.

Acknowledgments The authors wish to thank the National Council for Research (CNPq), Foundation for Research of the State of Bahia (FAPESB), and Foundation for Qualification of People for Superior Education (CAPES) for funding this research and providing scholarships.

\section{References}

Alonso-Diaz M, Torres-Acosta JFJ, Sandoval-Castro CA, Capetillo-Leal C, Brunet S, Hoste H (2008) Effects of four tropical tanniniferous plant extracts on the inhibition of larval migration and the exsheathment process of Trichostrongylus colubriformis infective stage. Vet Parasitol 153:197-192. doi:10.1016/j.vetpar.2008.01.011

Aoudia H, Ntalli N, Aissani N, Yahiaoui-Zaidi R, Caboni P (2012) Nematotoxic phenolic compounds from Melia azedarach against Meloidogyne incognita. J Agric Food Chem 60:11675-11680. doi: 10.1021/jf3038874
Aravind R, Eapen SJ, Kumar A, Dinu A, Ramana KV (2010) Screening of endophytic bacteria and evaluation of selected isolates for suppression of burrowing nematode (Radopholus similis Thorne) using three varieties of black pepper (Piper nigrum L.). Crop Prot 29:318324. doi:10.1016/j.cropro.2009.12.005

Argentieri MP, D'Addabbo T, Tava A, Agostinelli A, Jurzysta M, Avato P (2008) Evaluation of nematicidal properties of saponins from Medicago spp. Eur J Plant Pathol 120:189-197. doi:10.1007/ s10658-007-9207-8

Botura MB, Silva GD, Lima HG, Oliveira JVA, Souza TS, Santos JDG, Branco A, Moreira ELT, Almeida MAO, Batatina MJM (2011) In vivo anthelmintic activity of an aqueous extract from sisal waste (Agave sisalana Perr.) against gastrointestinal nematodes in goats. Vet Parasitol 177:104-110. doi:10.1016/j.vetpar.2010.11.039

Botura MB, Santos JDG, Silva GD, Lima HG, Oliveira JVA, Almeida MAO, Batatinha MJM, Branco A (2013) In vitro ovicidal and larvicidal activity of Agave sisalana Perr. (sisal) on gastrointestinal nematodes of goats. Vet Parasitol 192:211-217. doi:10.1016/j. vetpar.2012.10.012

Bridge J, Gowen R (1993) Visual assessment of plant parasitic nematode and weevil damage on bananas and plantain. In: Gold CS, Gemmill $\mathrm{B}$ (eds) Biological and integrated control of highland banana and plantain pests and diseases. Cotonou, Benin, Africa. pp 147-154

Candido V, D'Addabbo T, Basile M, Castronuovo D, Miccolis V (2008) Greenhouse soil solarization: effect on weeds, nematodes and yield of tomato and melon. Agron Sustain Dev 28:221-230. doi:10.1051/ agro:2007053

Castillo LE, Ruepert C, Solis E (2000) Pesticide residues in the aquatic environment of banana plantation areas in the North Atlantic Zone of Costa Rica. Environ Toxicol Chem 19:1942-1950. doi:10.1002/ etc. 5620190802

Chen PY, Chen CH, Kuo CC, Lee TH, Kuo YH, Lee CK (2011) Cytotoxic steroidal saponins from Agave sisalana. Planta Med 77: 929-933. doi:10.1055/s-0030-1250672

Coolen NW, D'Herde CJ (1972) A method for the quantitative extraction of nematodes from plant tissue. State Agricultural Research Centre, Belgium

Domingues LF, Botura MB, Cruz ACF, Yuki CC, Silva GD, Costa MS, Moreira ELT, Meneses IDS, Branco A, Almeida MGAR, Almeida MAO, Batatinha MJM (2010) Evaluation of anthelmintic activity of liquid waste of Agave sisalana (sisal) in goats. Rev Bras Parasit 19: 270-272. doi:10.1590/S1984-29612010000400018

Francis G, Kerem ZHPS, Becker K (2002) The biological action of saponins in animal systems. A review. Brit J Nutr 88:587-605. doi:10.1079/BJN2002725

Hounzangbe-Adote MS, Paolini V, Fouraste I, Moutairou K, Hoste H (2005) In vitro effects of four tropical plants on three life-cycle stages of the parasitic nematode, Haemonchus contortus. Res Vet Sci 78:155-160. doi:10.1016/j.rvsc.2004.05.009

Hu C, Qi Y (2013) Effective microorganisms and compost favor nematodes in wheat crops. Agron Sustain Dev 33:573-579. doi:10.1007/ s13593-012-0130-9

Hussey RS, Barker KR (1973) A comparison of methods of collecting inocula of Meloidogyne spp., including a new technique. Plant Dis Rep 57:1025-1028

Jenkins WR (1964) A rapid centrifugal-flotation technique for extracting nematodes from soil. Plant Dis Rep 48:692

Kosma P, Ambanga Z, Begoude BAD, Ten Hoopenb GM, Kuate J, Akoaa A (2011) Assessment of nematicidal properties and phytochemical screening of neem seed formulations using Radopholus similis, parasitic nematode of plantain in Cameroon. Crop Prot 30: 733-738. doi:10.1016/j.cropro.2011.02.026

López-Lima D, Sánchez-Nava P, Carrión G, Núñez-Sánchez A (2013) $89 \%$ reduction of a potato cyst nematode population using biological control and rotation. Agron Sustain Dev 33:425-431. doi:10. 1007/s13593-012-0116-7 
Mai WF, Mullin PG (1996) Plant-parasitic nematodes: a pictorial key to genera. Cornell University Press, Ithaca

Nasu EGC, Pires E, Fermentini HN, Furlanetto C (2010) Effect of manipueira on Meloidogyne incognita through in vitro and in vivo essays on tomatoes in greenhouse. Trop Plant Pathol 35:32-36. doi: 10.1590/S1982-56762010000100005

Oka Y, Nacar S, Putievsky E, Ravid U, Zohara Y, Spiegel Y (2000) Nematicidal activity of essential oils and their components against the root nematode. Phytopathology 90:710-715. doi:10.1094/ PHYTO.2000.90.7.710

Olabiyi TI, Oyedumade EEA, Ibikunle GL, Ojo OA, Adesina GO, Adelasoye KA, Ogunniran TA (2008) Chemical composition and bio-nematicidal potential of some weed extracts on Meloidogyne incognita under laboratory conditions. Plant Sci Res 1:30-35

Quénéhervé P (2009) Integrated management of banana nematodes. In: Ciancio A, Mukerji KG (eds) Integrated management of fruit crops and forest nematodes. Springer, The Netherlands, pp 3-61

Schenkel EP, Gosmann G, Athayde ML (2010) Saponinas. In: Simões CMO, Schenkel EP, Gosmann G, Mello JCP, Mentz LA, Petrovick
PR (eds) Farmacognosia: da planta ao medicamento. Editora da UFSC, Porto Alegre/Florianópolis, pp 711-740

Seinhorst JW (1967) The relationships between population increase and population density in plant-parasitic nematodes. II. Sedentary nematodes. Nematologica 13:157-171

Silveira RX, Chagas ACS, Botura MB, Batatinha MJM, Katiki LM, Carvalho CO, Bevilaqua CML, Branco A, Machado EAA, Borges SL, Almeida MAO (2012) Action of sisal (Agave sisalana, Perrine) extract in the in vitro development of sheep and goat gastrointestinal nematodes. Exp Parasitol 131:162-168. doi:10.1016/j.exppara. 2012.03.018

Suinaga FA, Silva ORRF, Coutinho WM (2006) Cultivo de Sisal na região Semi-árida do nordeste brasileiro. Campina Grande, EMBRAPA Algodão, $\mathrm{p} 42$

Tixier P, Chabrier C, Malézieux E (2007) Pesticide residues in heterogeneous plant populations, a model-based approach applied to nematicides in banana (Musa spp.). J Agric Food Chem 55:2504-2508. doi:10.1021/jf062710f

Wezel A, Casagrande M, Celette F, Vian JF, Ferrer A, Peigné J (2014) Agroecological practices for sustainable agriculture. A review. Agron Sustain Dev 34:1-20. doi:10.1007/s13593-013.0180-7 